\title{
Media Pembelajaran Ramah Lingkungan Sekolah Dasar Negeri Inklusi Di Pekanbaru Di Era Revolusi Industri 4.0
}

\author{
Ahmad Denico \\ IAI Dar Aswaja \\ Rokan hilir \\ ahmad.denico@gmail.com
}

\section{Abstrak}

Era revolusi industri 4.0 terkenal dengan perkembangan tekhnologi yang begitu pesat. Perkembangan ini harus diiringi dengan keseimbangan lingkungan. Perkembangan tekhnologi yang tidak ramah lingkungan menjadi masalah bagi masyarakat selain itu permasalahan sampah plastik yang juga sama meresahkannya. Permasalahan lingkungan tidak hanya meresahkan masyarakat secara umum saja namun juga merembes kepada lingkungan pendidikan untuk itu sebagai pendidik kita harus memanfaatkan barang-barang bekas untuk dijadikan media pembelajaran. Jurnal ini bertujuan untuk mengetahui media pembelajaran ramah lingkungan yang dapt dimanfaatkan oleh guru untuk menyampaikan materi pembelajaran yang menari perhartian siswa dikelas. Media pembelajaran ramah lingkungan merupakan media yang memanfaatkan barang-barang bekas untuk dijadikan sebagai alat penyampai materi untuk memusatkan perhatian belajar siswa. Ada beberapa media ramah lingkungan yang dapat dimanfaatkan oleh guru diantaranya: memanfaatkan botol bekas untuk dijadikan model alat pernafasan manusia, kotak bekas dijadikan sebagai model jam, botol aqua bekas dijadikan sebagai model media transportasi dan yang lainnya.

\section{Abstract}


The era of the industrial revolution 4.0 is famous for the rapid development of technology. This development must be accompanied by environmental balance. The development of technology that is not environmentally friendly becomes a problem for the community besides the problem of plastic waste which is equally disturbing. Environmental problems not only disturb society in general but also seeped into the educational environment for that, as educators, we must utilize used items to be used as learning media. This journal aims to determine the environmentally friendly learning media that can be used by teachers to deliver learning material that dances students in the class. An environmentally friendly learning media is a media that utilizes used goods to be used as a material delivery tool to focus on student learning. There are several environmentally friendly media that can be used by teachers including utilizing used bottles to be used as models for human breathing equipment, used boxes used as clock models, used aqua bottles used as transportation media models and others.

\section{Kata Kunci: Media Pembelajaran Ramah Lingkungan, Industri 4.0}

Keywords: Environmentally Friendly Learning Media, Industry 4.0

\section{A. PENDAhuluan}

Pendidikan merupakan usaha yang bertujuan untuk memberikan arahan kepada peserta didik untuk memperoleh kemajuan secara lahir dan batin dalam mengahdapi pengaruh lingkungan dan menjadikan manusia merdeka sebagai anggota masyarakat. ${ }^{1}$ Pendidikan tidak mengenal ras, suku, bangsa dan agama

${ }^{1}$ Ki Hadjar Dewantara. (2011). Karya Ki Hadjar Dewantara Bagian Pertama Pendidikan. Yogyakarta: Penerbit Yayasan Persatuan Tamansiswa. h.3 
semuanya memiliki hak yang sama inilah yang disebt dengan keterbukaan sesuai dengan tujuan akhir pendidikan yang dicetuskan oleh UNICEV bahwa learning to live together atau belajar adalah untuk bisa hidup saling berdampingan satu sama lainnya.

Pendidikan ditingkat dasar (SD) merupakan fase yang paling penting dan harus mendapatkan perhatian lebih karena ini merupakan landasar dasar pertama untuk menggapai pendidikan yang lebih tinggi untuk itu pendidikan dasar harus bersifat terbuka untuk semua hal ini yang menjadi dasar penyelenggaraan sekolah inklusi. SD inklusi adalah pendidikan dasr yang menerapkan konsep inklusif, semangat terbuka bagi siapa saja untuk mendapatkan hak yang sama tanpa memandang suku, ras,budaya, agama dan bangsa. Pendidikan inklusi sudah diatur dalam Permendiknas nomor 70 tahun 2009 menyatakan seluruh sekolah di Provinsi, maupun Kabupaten/kota wajib menyediakan pendidikan inklusif. Pendidikan inklusif harus terseduia dari tingkat SD, SMP dan SMA. ${ }^{2}$

Permasalahan yang terjadi saat ini adalah masih rendahnya kompetensi guru terutama kompetensi pedagogik. $^{3}$ Kompetensi pedagogik guru SD adalah menyelenggarakan pembelajaran yang mendidik dalam hal menggunakan media pembelajaran sesuai dengan karakteristik siswa untuk mencapai tujuan pembelajaran secara utuh. ${ }^{4}$ Seharusnya seorang guru yang memiliki kompetensi yang bagus harus memaksimalkan kompetensi tersebut untuk mengatur, mengelola materi pembelajaran agar dapat disampaikan secara teatur dan dapat menarik

2 Peraturan Menteri Pendidikan Nasional Nomor 70 Tahun 2009

${ }^{3}$ Suraji, I. (2012). Urgensi Kompetensi Guru. Edukasia Islamika, h.10

${ }^{4}$ Permendiknas Nomor 16 Tahun 2007 tentang Kompetensi Guru 
perhatian belajar siswa dikelas. ${ }^{5}$ Pembelajaran merupakan bagian terpenting untuk mencapai keberhasilan tujuan pendidikan, keberhasilan tersebut tidak bisa dengan sendirinya melainkan harus bersinergi antara guru, siswa, media, strategi, metode, sarana dan sumber belajar kebersinergian ini nantinya yang akan mencapai tujuan pendidikan mapun tujuan pembelajarannya. ${ }^{6}$

Era revolusi industri 4.0 yang sarat akan tekhnologi menuntut semua ruang untuk menyesuaikan dengan perkembangan tekhnologi, salah satunya ruang pendidikan, era ini menuntut guru untuk terampil dalam memanfaatkan perkembangan tekhnologi ini untuk dijadikan sebagai media pembelajaran agar siswa dapat belajar dengan maksimal. Selain sisi positif ada sisi negatif dari perkembangan tekhnologi yakni tekhnologi yang tidak dikembangkan tidak semestinya yang dapat merusak tatanan lingkungan atau dengan kata lain tidak ramah lingkungan, yakni tentang pengolahan sampah yang belum maksimal ini merupakan kendala yang dihadapi sekolah dasar yang menyatakan sebagai sekolah Adiwiyata. ${ }^{7}$ Maka diera industri 4.0 ini media ramah lingkungan untuk tingkat dasar bisa dikatakan media yang tepat untuk dimanfaatkan sebagai alat penyampai materi kepada anakanak ditingkat dasar.

5 Ayu Rahayu. (2014). Penerapan Konsep Pendidikan Ki Hadjar Dewantara Dalam Pembelajaran Untuk Membentuk Peserta Didik Berkarakter Cerdas dan Berintegritas. Jurnal Edukasi UIN Walisongo Semarang Volume XI nomor 1 September 2015 .h.80

6 Ahmad Tarmiji. (2015) Menuju Green School: Penerapan Kurikulum Pembelajaran Berwawasan Lingkungan di Institusi Pendidikan.h.11

${ }^{7}$ Nani Aprilia. Evaluasi Pengelolaan Sarana Pendukung yang Ramah Lingkungan pada Program Adiwiyata di SMP Muhammadiyah Di Kota Yogyakarta. Prosiding Seminar Nasional Pendidikan Biologi 2015, h. 747 
J-Al-Mutharahah : Vol. 17 No. 1 Januari-Juni 2020

\section{B. METODE PENELITIAN}

Pendekatan dalam penelitian ini adalah pendekatan kualitatif. Metodologi kualitatif adalah prosedur penelitian yang menghasilkan data deskriptif berupa kata-kata tertulis atau lisan dari orang-orang dan perilaku yang dapat diamati. ${ }^{8}$ Sementara itu Cresswell penelitian kualitatif adalah penelitian yang dibimbing oleh paradigma kualitatif didefinisikan sebagai suatu proses penelitian untuk memahami masalah-masalah manusia atau sosial dengan menciptakan gambaran menyeluruh dan kompleks yang disajikan dengan kata-kata. Teknik pengumpulan data dalam penelitian ini menggunakan teknik Observasi, wawancara dan dokumentasi. Teknik analisis data mengggunakan analisis data induktif yaitu proses menganalisis yang berangkat dari fakta-fakta khusus kemudian ditarik generalisasi yang bersifat umum.

\section{PEMBAHASAN}

\section{Media Pembelajaran}

Media adalah perantara atau pengantar pesan dari pemberi ke penerima. Dalam kontek pembelajaran media adalah segala sesuatu yang digunakan untuk menyampaikan pembelajaran. Media pembelajaran adalah segala sesuatu benda yang digunakan sebagai perantara dalam proses pembelajaran untuk mencapai tujuan pembelajaran yang diharapkan.

Menurut Ali media pembelajaran terbagi kedalam beberapa bagian diantaranya media audio, visual dan audio visual.

8 Lexy . J. Moleong, Metodologi Penelitian Kualitatif Edisi Revisi. (Bandung: Remaja Rosda Karya, 2012), h. 4 
J-Al-Mutharahah : Vol. 17 No. 1 Januari-Juni 2020

\section{Fungsi Media Pembelajaran}

Fungsi utama media pembelajran adalah sebagai alat bantu untuk mengajar yang akan berpengaruh terhadap iklim, kondisi dan lingkungan belajar. Penggunaan media pada orientasinya sangat membantu keefektifan penyampaian pesan pelajaran pada saati itu disamping itu juga dapat meningkatkan motivasi belajar anak didik. $^{9}$

Menurut Kemp dan Dayton ada tiga fungsi utama penggunaan media pembelajaran yaitu: memotivasi minat atau tindakan, menyajikan informasi dan memberi intruksi. ${ }^{10}$

Sedangkan menurut Azhar Arsyad fngsi media itu ada empat yaitu: fungsi Atensi menarik perhatian peserta didik, fungs afektif mengunggah emosi dan sikap peserta didik untuk menikmati pembelajaran, fungsi kognitif memperlancar capain tujuan pembelajaran, fungsi kompensatoris mengakomodasi peserta didik yang lemah dan lambat menerima materi pembelajaran. ${ }^{11}$

\section{Pemilihan Media Pembelajaran}

Kriteria pemilihan media bersumber dari konsep bahwa media merupakan bagian dari instruksional secara keseluruhan adapun kriteria yang perlu diperhatikan dalam memilih media diantaranya: sesuai dengan tujuan pembelajaran, tepat untuk mendukung isi materi pelajaran, praktis untuk digunakan, dan guru trampil untuk menggunakannya. ${ }^{12}$

9 Azhar Arsyad, Media Pembelajaran, (Jakarta: Raja Grafindo Persada, 2013), cet. 16, h.3

10 Cecep Kustandi dan Bambang Sutjipto, Media Pembelajaran Manual dan Digital, (Bogor: Ghalia Indonesia, 2013), ed. II,h.20

11 Op Cit. Azhar arsyad.h.20

12 Op cit Cecep Kustandi dan Bambang Sutjipto,h.80 


\section{Media Pembelajaran Ramah Lingkungan}

Media ramah lingkungan adalah media yang dibuat dengan mempertimbangkan faktor-faktor pendukung keseimbangan lingkungan. Media ini selain dijadikan alat untuk menyampaikan materi oleh pendidika tetapi media ini juga digunakan untuk mengurangi limbah atau sampah yang selama ini menjadi permasalahan yang belum ada solusinya sampai sekarang.

Pada pelaksanaannya guru dapat memanfaatkan barang-barang bekas seperti botol plasik, botol kaca, plastik bekas dan yang lainnya. Tadi sudah dijelaskan sebelumnya mengapa guru itu harus memiliki kompetensi yang bagus salah satu fungsinya adalah untuk menuntut kreatifitas seornag guru dalam membat media pembelajaran. Dengan kreatifitas yang dimilki oleh guru mampu menyulap barang-barang bekas yang notaben nya sudah menjadi sampah untuk dijadikan sebagai media pembelajaran. Pemanfaatan barang bekas ini sebenarnya bukan hal baru ini sudah pernah dilakukan oleh guru-guru terdahulu yang dengan keterbatasan sarana yang mereka miliki sehingga guru harus dituntut kreatif dalam menyampaikan materi pembelajarannya sebelum kedatangan media modern seperti sekarang. ${ }^{13}$

Media pembelajaran untuk tingkat SD untuk mengajak anak-anak lebih kreatif lagi tidak ada salahnya kita sebagai seorang guru untuk membuat media yang ramah lingkungan detengah media modern ang berkembang pada era indusri ini. Media yang digunakan dapat bersal dari barang-barang yang murah berasal dari botol plastik, botol kaca, kotak kardus,

13 Siarni, S., Pasaribu, M., \& Rede, A. (2015). Pemanfaatan Barang Bekas Sebagai Media Pembelajaran Untuk Meningkatkan Hasil Belajar IPA Siswa Kelas IV SDN 07 Salule Mamuju Utara. Jurnal Kreatif Tadulako, 3(2). 
kaleng bekas dan lain sebagainya. Mengapa kita perku mengembangkan media ramah lingkungan ini karena anak tingkat Sekolah Dasar pada tahapan berfikirnya masih pada tahap berfikir konkrit maka sudah sepatutnya kita mengajak mereka untuk berhubungan langsung dengan media atau alat pembelajaran yang dapat disentuh dilihat untuk mengembangkan tahapan berfikir anak tingkat dasar. Jadi pemilihan alat belajar sederhana (media ramah lingkungan) bukan karena harganya yang murah tetapi untuk kepentingan perkembangan belajar siswa. ${ }^{14}$

\section{HASIL PENELITIAN}

Berdasarkan hasil observasi pada Sekolah Dasar Negeri 26 Pekanbaru yang merupakan sekolah inklusi dengan rogram adiwiyata ditemukan media ramah lingkungan yang sudah dimanfaatkan oleh guru dalam pembelajaran diantaranya:

1. Membuat model alat pernafasan manusia dengan memanfaatkan botol bekas
a. Botol Aqua
b. Balon
c. Selang

14 Budiningsih, C. A. (1995). Strategi Menggunakan Media Pengajaran bagi Pendidikan Dasar. Cakrawala Pendidikan.h.69 


\section{Gambar D.1}

Alat Pernapasan Pada Manusia

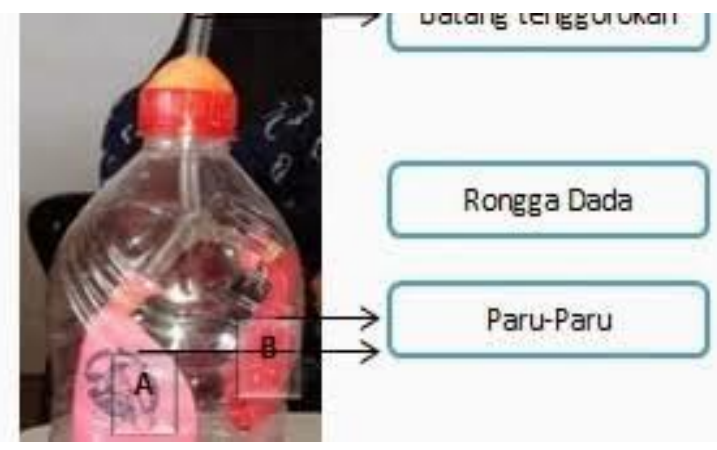

2. Membuat jam dinding dari kotak bekas
a. Kotak kardus
b. Spidol
c. Jarum
d. Dan krayon

Gambar D.2

Jam Dinding

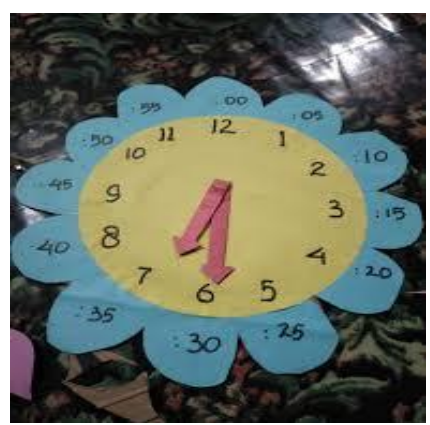

3. Membuat Mobil dari Botol Plastik
a. Botol Plastik
b. Selang / pipet 
J-Al-Mutharahah : Vol. 17 No. 1 Januari-Juni 2020

c. Lidi/tusuk gigi

d. Karet

e. Lem

f. Kabel ti

Gambar D.3

Transportasi

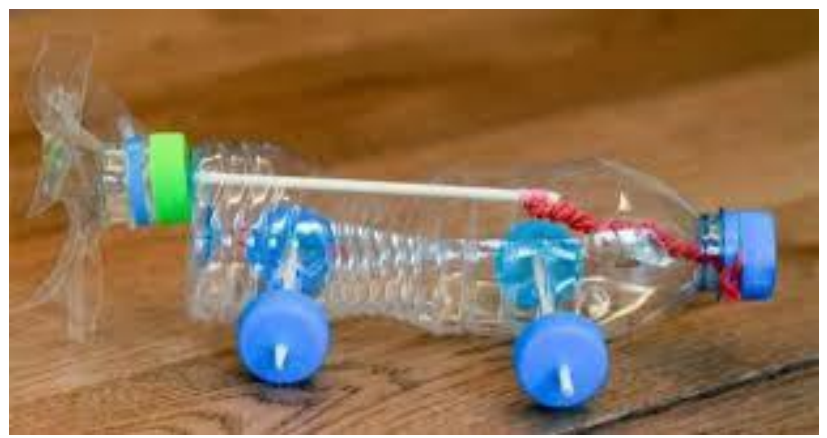

4. Membuat Kompas Sederhana
a. Piring,
b. Sendok
c. Air
d. Penggaris
e. Spidol

Gambar D.4

Kompas dari Piring

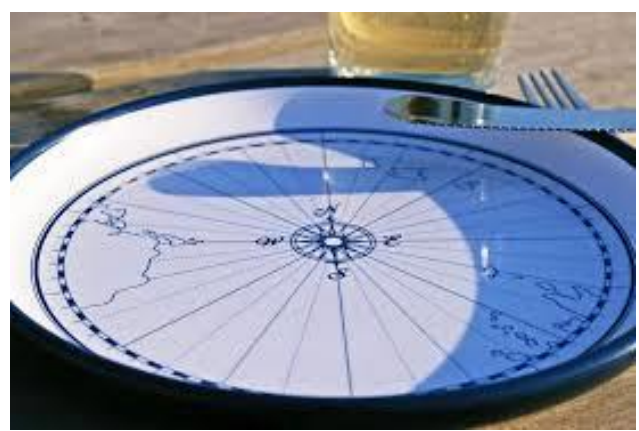


5. Membuat Dakon Matematika

a. Triplek/karton sterofom

b. Mangkuk agar-agar plastik

c. Biji buah / kancing baju dll

d. Pita

e. Calender bekas untuk nomor dan nama dakota Gambar D.5

Dakon matematika

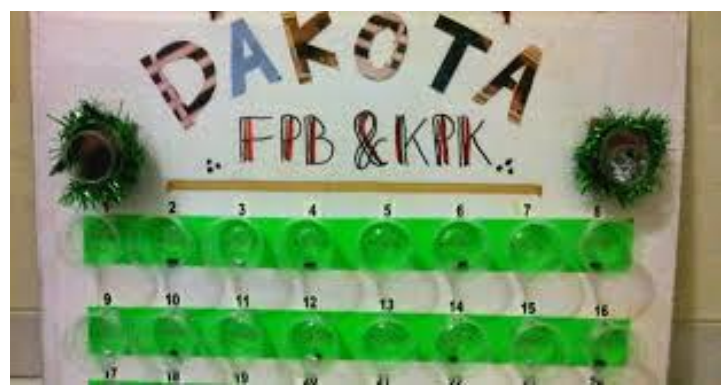

6. Membuat jaring-jaring bangun ruang

a. Bambu

b. Paku

c. Tali

d. Kertas minyak

Gambar D.6

Jaring-jaring bangun ruang

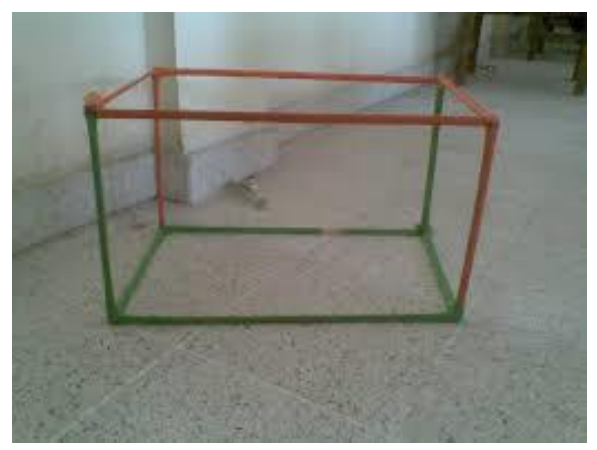




\section{E. KESIMPULAN}

Media pembelajaran ramah lingkungan dapat dikembangkan oleh guru di Sekolah Dasar yang berbasis inklusif bukan karena harganya yang murah melainkan kebrmanfaatannya yang sangat luar biasa kita ketahui bahwa anak-anak tingkat dasr tahapan berfikrinya pada kategori konkrit mereka dapat memahamiapa yang mereke lihat, mereka raba, mereka pegang. Mereka belum bisa memahami segala seuatu yang bersifat abstrak. Maka sudah seharusnya kita sebagai seorang guru untuk mendesain materi dengan memanfaatkan media pembelajaran yang perlu disesuaikan dengan tahapan perkemangan berfikir mereka.

Media ramah lingkungan dirasa sangat cocok untuk diterapkan di Sekolah dasar inklusif di era revolusi industri 4.0. walaupun era ini dikenal dengan kemajuan tekhnologinya tapi anak-anak untuk tingkat dasar jika dimanfaatkan dengan media berbasis tekhnologi yang tanpa pengawasan yang ketat ii akan berdampak buruk untuk perkembangan anak tersebut. Maka perlunya kepala sekolah guru dan pemangku kepentingan pendidikan lainnya untuk mengatur ulang tentang penggunaan media yang tepat sesuia dengan usia perkembangan mereka. Intinya media ramah lingkungan sangat tepat digunakan untuk anak-anak tingkat dasar dalam pembelajaran dikelas namun harus disesuaikan dengan materi pelajarannya. 
J-Al-Mutharahah : Vol. 17 No. 1 Januari-Juni 2020

\section{REFERENSI}

Ahmad Tarmiji. (2015) Menuju Green School: Penerapan Kurikulum Pembelajaran Berwawasan Lingkungan di Institusi Pendidikan.

Ayu Rahayu. (2014). Penerapan Konsep Pendidikan Ki Hadjar Dewantara Dalam Pembelajaran Untuk Membentuk Peserta Didik Berkarakter Cerdas dan Berintegritas. Jurnal Edukasi UIN Walisongo Semarang Volume XI nomor 1 September 2015

Azhar Arsyad, Media Pembelajaran, (Jakarta: Raja Grafindo Persada, 2013), cet. 16

Cecep Kustandi dan Bambang Sutjipto, Media Pembelajaran Manual dan Digital, (Bogor: Ghalia Indonesia, 2013), ed. II

Ki Hadjar Dewantara. (2011). Karya Ki Hadjar Dewantara Bagian Pertama Pendidikan. Yogyakarta: Penerbit Yayasan Persatuan Tamansiswa.

Lexy . J. Moleong, Metodologi Penelitian Kualitatif Edisi Revisi. (Bandung: Remaja Rosda Karya, 2012)

Nani Aprilia. Evaluasi Pengelolaan Sarana Pendukung yang Ramah Lingkungan pada Program Adiwiyata di SMP Muhammadiyah Di Kota Yogyakarta. Prosiding Seminar Nasional Pendidikan Biologi 2015

Peraturan Menteri Pendidikan Nasional Nomor 70 Tahun 2009

Permendiknas Nomor 16 Tahun 2007 tentang Kompetensi Guru

Suraji, I. (2012). Urgensi Kompetensi Guru. Edukasia Islamika

Siarni, S., Pasaribu, M., \& Rede, A. (2015). Pemanfaatan Barang Bekas Sebagai Media Pembelajaran Untuk Meningkatkan Hasil Belajar IPA Siswa Kelas IV SDN 07 Salule Mamuju Utara. Jurnal Kreatif Tadulako, 3(2). 